\title{
Exigências nutricionais de bezerros da raça Holandesa alimentados com concentrado e feno de capim-elefante ${ }^{1}$
}

\section{Paulo Valter Nunes Nascimento ${ }^{2}$, Fabiano Ferreira da Silva ${ }^{3}$, Cristina Mattos Veloso ${ }^{3}$, Paulo Bonomo ${ }^{4}$, Fábio Andrade Teixeira ${ }^{2}$, João Gonsalves Neto ${ }^{3}$}

\footnotetext{
${ }^{1}$ Pesquisa financiada pela Universidade Estadual do Sudoeste da Bahia.

2 Pós-graduação em Zootecnia - UESB.

${ }^{3}$ Departamento de Tecnologia Rural e Animal - UESB.

${ }^{4}$ Departamento de Estudos Básicos e Instrumentais - UESB.
}

RESUMO - Foram utilizados 13 bezerros machos da raça Holandesa, com idade média de 14 dias. Três animais foram abatidos no início do experimento (referência) e os outros dez foram distribuídos aleatoriamente em dois tratamentos (ração farelada ou peletizada) e abatidos aos 112 dias de idade para determinação das exigências nutricionais. Foram ajustadas equações de regressão do logaritmo da quantidade corporal de proteína, gordura e energia em função do peso de corpo vazio (PCVZ). As exigências líquidas de proteína e energia para ganho de 1 kg de PCVZ foram obtidas por derivação das equações de predição da composição corporal. Os conteúdos de proteína, gordura e energia aumentaram de acordo com o peso corporal. Os requerimentos líquidos de proteína e energia para ganho de peso de corpo vazio (GPCVZ) elevaram quando o PCVZ variou de 25,74 até $85,81 \mathrm{~kg}$. Foi obtida a equação para estimar a proteína retida em função do ganho médio diário (GMD) e da energia retida (ER): PR $=-0,297083+4,19797$ ganho de peso corporal em jejum $(\mathrm{GPCJ})+0,0926327$ ER $\left(R^{2}=0,92\right)$. A equação obtida para descrever a relação entre a energia retida (ER), em Mcal, e o ganho diário de PCVZ (GPCVZ), em kg, para determinado PCVZ a partir dos dados deste trabalho, foi a seguinte: ER = 0,1004 $\times$ PCVZ $0,75 \times \mathrm{GDPCVZ}^{0,5552}$. Os valores de energia líquida de mantença (ELm) variaram de 1,10 para 2,72 Mcal/dia e energia líquida para ganho (ELg) de 1,42 para 2,46 Mcal/dia quando o peso corporal aumentou de 30 para $100 \mathrm{~kg}$. Dos 28 aos 112 dias de idade, aumenta a composição de proteína, gordura e energia no corpo vazio de bezerros machos da raça Holandesa.

Palavras-chave: peso corporal, peso de corpo vazio

\section{Nutritional requirements of Holstein calves fed concentrate and elephant grass hay}

ABSTRACT - Thirteen male Holstein calves with average age of 14 days were used. Three animals were slaughtered at the beginning of the experiment (reference) and ten others were randomly distributed in two treatments (ground or pelleted feed), and slaughtered at 112 days of age to determine the nutritional requirements. Regression equations of the logarithm of the amount of protein, fat and energy in the body were fitted as a function of the empty of body weight (EBW). The net protein and energy requirements for $1 \mathrm{~kg}$ gain of EBW were obtained by deriving the prediction equations of body composition. There were increases in protein, fat and energy contents with increase in body weight. The net protein and energy requirements for empty body weight gain (GEBW) increased when EBW varied from 25.74 to $85.81 \mathrm{~kg}$. The equation was obtained to estimate the retained protein as a function of the mean daily gain (DMG) and retained energy (RE): $\mathrm{RP}=-0.297083+4.19797$ gain of fasting body weight $(\mathrm{FGBW})+0.0926327 \mathrm{RE}$. The equation obtained to describe the relationship between retained energy (RE), in Mcal, and EBW daily gain (DGEBW), in kg, for a determined EBW starting from the data of the present study was the following: $\mathrm{RE}=0.1004 \times \mathrm{EBW}^{0.75} \times \mathrm{EBWG}^{0.5552}$. The NEm varied from 1.10 to $2.72 \mathrm{Mcal} /$ day and NEg from 1.42 to $2.46 \mathrm{Mcal} /$ day when the body weight increased from 30 to $100 \mathrm{~kg}$. From 28 to 112 days of age there were protein, fat and energy increases in the empty body composition of the Holstein male calves.

Key Words: body weight, empty body weight

\section{Introdução}

O desmame precoce é uma das práticas utilizadas na criação de bezerros que pode possibilitar tanto a boa criação das fêmeas de reposição quanto o aproveitamento do leite não destinado aos bezerros para a venda (Lopes et al., 1998).

Para determinação da composição corporal, existem dois métodos: o do abate do animal, seguido pela moagem 
da carcaça para análises laboratoriais, que, de acordo com Van Soest (1994), é um procedimento trabalhoso e dispendioso; e o do abate e da amostragem da carcaça, que é adotado por vários pesquisadores.

A composição física da carcaça se modifica à medida que o animal cresce. Os músculos representam alta porcentagem do peso total ao nascimento, que aumenta ligeiramente e começa a decrescer à medida que se inicia a fase de deposição de gordura. Segundo Armstrong \& Blaxter (1983), o requisito de energia para mantença corresponde ao nível de energia a ser suprido diariamente pelos alimentos, sem alteração do peso corporal.

O requisito de proteína é fracionado em componentes para mantença e para ganho. A mantença constitui-se das perdas obrigatórias de nitrogênio $(\mathrm{N})$ na urina e nas fezes, enquanto o ganho é representado pelo nitrogênio retido nos tecidos.

Para determinação das exigências nutricionais, o NRC (2001) não faz distinções entre bezerros machos e fêmeas, pois as diferenças são negligenciáveis até $100 \mathrm{~kg}$ de peso corporal. A literatura é escassa em informações sobre as exigências nutricionais de bezerros jovens, principalmente na fase de aleitamento, originários de rebanhos leiteiros e criados para produção de carne.

Entre produtores e técnicos, existem opiniões diferentes quanto à utilização da ração farelada ou peletizada para bezerros em aleitamento, embora a ração peletizada seja de maior custo. Gonsalves Neto (2004), utilizando ração farelada ou peletizada para bezerros machos de origem leiteira, concluiu que não houve efeito da característica da ração no desempenho dos animais.

O objetivo neste estudo foi determinar as exigências líquidas e dietéticas de bezerros em crescimento, provenientes de rebanho leiteiro, submetidos a desmama precoce e alimentados com concentrado e feno de capim-elefante.

\section{Material e Métodos}

O experimento foi conduzido no Setor de Bovinocultura de Leite do Departamento de Tecnologia Rural e Animal da Universidade Estadual do Sudoeste da Bahia, localizada no município de Itapetinga, Bahia. Foram utilizados 13 bezerros machos puros de origem, da raça Holandesa, com peso corporal médio de $48,17 \mathrm{~kg}$ e aproximadamente 14 dias de idade, identificados com brincos numerados, adquiridos de vários produtores de leite da região.

Os animais foram alojados em baias individuais cobertas, com piso de concreto, providas de cocho individual de concreto para fornecimento do volumoso e cochos de madeira para o fornecimento do concentrado, e bebedouro automático, comum às duas baias.

Durante os 14 primeiros dias de vida, os bezerros receberam os cuidados tradicionalmente utilizados nas propriedades de origem, como: corte e cura do umbigo com solução de iodo por, no mínimo, três dias; fornecimento de 4 litros de colostro da primeira ordenha, nas primeiras 6 horas de vida do bezerro, e fornecimento de 4 litros diários de colostro diluído em água, duas partes de colostro para uma parte de água, a partir do segundo dia de vida.

A partir do 14 - dia de vida, os animais passaram por um período de adaptação de 14 dias, durante os quais foram identificados, tratados contra ecto e endoparasitos e alimentados com concentrado farelado ou peletizado e sucedâneo (Tabelas 1 e 2). No início do experimento, 10 animais foram pesados e distribuídos em dois tratamentos, em delineamento experimental inteiramente casualizado com cinco repetições. Os tratamentos consistiram de dois tipos de concentrado (farelado e peletizado). Para completar as informações necessárias para determinação dessas exigências, foram escolhidos, aleatoriamente, três animais para servirem de referência na composição corporal inicial.

O experimento foi conduzido em duas fases. A primeira foi o período de aleitamento, iniciado quando os animais atingiram 28 dias de idade e encerrado aos 70 dias de idade, com duração total de 42 dias (seis semanas). O segundo período, de pós-desmama, teve duração de mais 42 dias (seis semanas) perfazendo, todo o experimento, 84 dias ou 12 semanas.

No período de aleitamento, os bezerros receberam 4 litros reconstituídos de sucedâneo, de nome comercial "Sprayfo" (1 parte de sucedâneo para 7 partes de água), e concentrado à vontade, a partir da segunda semana de vida. Após o desmame, os bezerros receberam feno de capimelefante (Pennisetum purpureum Schum.) à vontade e mais 2,0 kg de concentrado. O capim-elefante utilizado na confecção do feno foi cortado manualmente, rente ao solo, por volta de 80 dias de idade, picado em picadeira estacionária, desidratado ao sol e posteriormente acondicionado em sacos de náilon. O concentrado foi formulado para propiciar ganho de peso de $0,60 \mathrm{~kg} / \mathrm{dia}$, conforme estimativas do NRC (2001). A partir do concentrado farelado, foi produzido o concentrado peletizado em peletizadora marca Chavante Modelo 7,5HP (Tabela 1).

A administração de vermífugo oral foi realizada aos 30 e 60 dias de idade dos bezerros e o controle dos ectoparasitas, de acordo com a incidência. Os animais foram pesados aos 28, 49, 70, 91 e 112 dias de idade, correspondendo ao início do experimento, meio da fase de aleitamento artificial, 
Tabela 1 - Composição dos concentrados, em \% da matéria seca

\begin{tabular}{lc}
\hline Ingrediente & $\%$ da matéria seca \\
\hline Milho grão moído & 44,08 \\
Farelo de soja & 39,23 \\
Farelo de trigo $_{\text {Sal mineral }^{1}}$ & 9,45 \\
Óleo de palma $^{\prime}$ & 4,00 \\
Bicarbonato de sódio $_{\text {Calcário calcítico }}$ & 2,00 \\
\hline
\end{tabular}

${ }^{1}$ Contendo por kg: Ca - 233 g; P - 80 g; Mg - 5 g; Na - 48 g; Co - 25 mg; Cu 380 mg; I - 25 mg; Mn - 1.080 mg; Se - 3,75 mg; Zn - 1.722 mg; vitamina A 300.000 UI; vitamina D - 55.000 UI; vitamina E - $200 \mathrm{mg}$.

desmama, meio da fase pós-desmama e final do experimento, respectivamente.

Para determinação das exigências nutricionais, foram utilizados 10 animais (cinco de cada concentrado). Três bezerros foram abatidos aos 28 dias de idade (gruporeferência) e serviram de referência para a composição corporal inicial.

Os três animais-referência foram abatidos no início do experimento (28 dias de idade) e os restantes, ao término (112 dias de idade). Antes do abate, os animais foram mantidos em jejum por 16 horas. Após o abate, o trato gastrintestinal foi esvaziado e lavado para determinação de seu peso, após escorrer a água. Para determinação do peso de corpo vazio (PCVZ), foram somados os pesos dos órgãos, das vísceras e das demais partes do corpo (carcaça, cabeça, couro, cauda, pés e sangue). A relação entre o PCVZ e o peso corporal (PC) dos animais-referência foi utilizada para a estimativa do PCVZ inicial dos animais mantidos no experimento.

Dentro de cada tratamento, foi sorteado um animal, do qual foram retirados a cabeça, um membro anterior e outro posterior para separação física de músculos, gordura, ossos e couro e posterior pesagem. A relação dos constituintes físicos na cabeça e nas patas desses animais foi utilizada para estimar o peso destes constituintes nos outros animais dos respectivos concentrados.
As amostras de sangue foram colhidas imediatamente após o abate, acondicionadas em recipiente de vidro e mantidas em estufa de ventilação forçada, a $55-60^{\circ} \mathrm{C}$, durante 72 horas, para determinação do teor de MS. Em seguida, foram trituradas em moinho de bola e acondicionadas em recipientes apropriados, para posteriores análises de nitrogênio total e extrato etéreo, conforme descrito por Silva \& Queiroz (2002); o teor de proteína foi obtido pelo produto entre o teor de nitrogênio total e o fator 6,25.

As amostras de rúmen, retículo, omaso, abomaso, intestino delgado, intestino grosso, gordura interna, mesentério, aparas (esôfago, traquéia e aparelho reprodutor), fígado, coração, rins, pulmões, língua, baço e carne industrial foram agrupadas de forma proporcional, para compor uma amostra de órgãos+vísceras.

As amostras de couro, órgãos+vísceras+gordura interna, tecido mole da carcaça inteira e ossos foram prédesengorduradas com éter de petróleo, conforme metodologia descrita por Kock \& Preston (1979). Após a determinação do teor de umidade e do pré-desengordura-mento, as amostras foram moídas finamente e armazenadas em recipientes adequados para posteriores análises de nitrogênio total, cinzas e extrato etéreo, conforme metodologias descritas por Silva \& Queiroz (2002). A gordura removida no pré-desengorduramento foi adicionada aos resultados obtidos para o EE determinando-se assim o teor total de gordura. A partir da obtenção dos teores de proteína, EE e do peso da amostra submetida ao pré-desengorduramento, determinaram-se os respectivos teores na matéria natural.

Os conteúdos corporais de gordura, proteína e água foram determinados de acordo com suas concentrações percentuais nos órgãos+vísceras, couro, sangue, cauda, cabeça, pés e constituintes separados (gordura, músculos e ossos). Estes últimos representaram a composição física e química da carcaça. As porcentagens de proteína, EE e água da carcaça foram calculadas multiplicando-se a composição física da carcaça pela composição química dos respectivos constituintes (músculo, ossos e gordura).

Tabela 2 - Composição nutricional dos concentrados, do sucedâneo e do feno

\begin{tabular}{|c|c|c|c|c|c|c|}
\hline Variável & \multicolumn{2}{|c|}{ Concentrado $^{1}$} & \multicolumn{2}{|c|}{ Concentrado $^{2}$} & Sucedâneo ${ }^{1}$ & Feno $^{2}$ \\
\hline Matéria seca (\%) & 87,81 & 87,12 & 88,43 & 88,12 & 89,57 & 91,40 \\
\hline Proteína bruta (\%MS) & 23,6 & 23,3 & 24,01 & 23,98 & 18,15 & 6,75 \\
\hline Extrato etéreo (\%MS) & 3,85 & 3,25 & 3,65 & 3,04 & 13,66 & 1,63 \\
\hline Fibra em detergente neutro (\%MS) & 11,74 & 11,81 & 11,74 & 11,81 & 0,79 & 81,16 \\
\hline
\end{tabular}

\footnotetext{
${ }^{1}$ Usado no período de aleitamento.

2 Usado no período pós-aleitamento.
} 
A determinação da energia corporal foi obtida a partir das quantidades corporais de proteína e gordura e seus respectivos equivalentes calóricos, conforme equação preconizada pela ARC (1980):

$$
\mathrm{CE}=5,6405 \mathrm{X}+9,3929 \mathrm{Y}
$$

em que: $\mathrm{CE}=$ conteúdo energético $(\mathrm{Mcal}) ; \mathrm{X}$ = proteína corporal (kg); e Y = gordura corporal (kg).

Os conteúdos de proteína, gordura e energia retidos no corpo dos animais foram estimados por meio de equações de regressão do logaritmo do conteúdo corporal de proteína, gordura e energia em função do logaritmo do PCVZ, segundo o ARC (1980), conforme o seguinte modelo:

$$
\mathrm{Y}=\mathrm{a}+\mathrm{bX}+\mathrm{e}
$$

em que: $\mathrm{Y}=$ logaritmo do conteúdo total de proteína $(\mathrm{kg})$, gordura (kg) ou energia (Mcal) retido no corpo vazio; a = constante; $b$ = coeficiente de regressão do logaritmo do conteúdo de proteína, gordura ou energia em função do logaritmo do PCVZ; X = logaritmo do PCVZ; e e = erro aleatório.

Para cada tratamento, as equações foram construídas adicionando-se os valores relativos aos animais-referência.

Derivando-se as equações de predição do conteúdo corporal de proteína, gordura ou energia em função do logaritmo do PCVZ, foram obtidas as equações de predição dos conteúdos de proteína, gordura ou energia por kg de ganho de PCVZ. As exigências líquidas de proteína e energia para ganho de $1 \mathrm{~kg}$ de PCVZ corresponderam aos respectivos conteúdos no ganho de corpo vazio e foram obtidas, juntamente com o conteúdo de gordura no ganho de corpo vazio, a partir de equação do tipo:

$$
\mathrm{Y}^{\prime}=\mathrm{b} \cdot 10^{\mathrm{a}} \cdot \mathrm{X}^{\mathrm{b}-1}
$$

em que: $\mathrm{Y}^{\prime}=$ conteúdo de gordura no ganho, ou exigência líquida de proteína ou energia; a e b = intercepto e coeficiente de regressão, respectivamente, das equações de predição dos conteúdos corporais de proteína, gordura ou energia; e X = PCVZ (kg).

Os requisitos de proteína metabolizável para mantença (PMm), ganho (PMg) e as exigências de proteína bruta (PB) foram obtidos segundo o NRC (2001), utilizando-se as equações:

1) $P M m=6,25[1 / 0,764(E+G+M * D)-M * D]$, em que: $\mathrm{E}=$ nitrogênio urinário endógeno $\left(\mathrm{g}=0,2 \times \mathrm{PC}^{0,75}\right) ; \mathrm{G}=$ conteúdo de nitrogênio do ganho (30 g/kg de ganho); $\mathrm{M}=$ nitrogênio metabólico fecal (g/dia $=2,46 \times$ consumo de matéria seca); $\mathrm{D}$ = consumo de matéria seca;

2) $\mathrm{PMg}=$ exigências líquidas/(0,834- $(\mathrm{PC} *(475 /$ 530)*0,00114), em que: PMg (proteína metabolizável para ganho; e

3) $\mathrm{PB}=\mathrm{PMt} / 0,8645$, em que PMt é proteína metabolizável total.
Para a conversão do PC em PCVZ, dentro do intervalo de pesos incluído no trabalho, foi calculada a regressão do PCVZ dos dez animais mantidos no experimento em função do seu peso corporal. Utilizou-se na conversão das exigências para ganho de PCVZ em exigências para ganho de PC o fator obtido a partir dos dados experimentais.

Foi efetuada uma equação de regressão entre a energia retida (ER) e o ganho diário de PCVZ (GDPCVZ), para determinado PCVZ, conforme preconizado pelo NRC (2001).

Os requisitos de energia metabolizável para mantença foram calculados pela equação: $\mathrm{EMm}=\mathrm{ELm} / 0,825$, segundo o NRC (2001). Como valores de energia metabolizável para ganho, foram utilizados os valores encontrados no próprio experimento. As exigências de NDT foram calculadas dividindo-se as exigências de EM pelas eficiências de utilização da energia digestível $(0,934)$, segundo o NRC (2001), obtendo-se as exigências de energia digestível (ED) e, posteriormente, dividindo-se as exigências de ED por 4,409.

Os resultados foram interpretados estatisticamente por meio de análises de variância e regressão, utilizando-se o Sistema de Análises Estatísticas e Genéticas - SAEG (Ribeiro Jr., 2001). As comparações entre as equações de regressão dos parâmetros foram avaliadas de acordo com a metodologia recomendada por Regazzi (1996) para testar identidade de modelos.

\section{Resultados e Discussão}

A relação obtida para estimar o PCVZ a partir do PC dos animais deste trabalho foi: $\mathrm{PCVZ}=\mathrm{PC} * 0,8581$, próximo ao valor de 0,891 recomendado pelo NRC (2001), 0,8975 por Silva et al. (2002a) e 0,8021 por Carvalho et al. (2003).

$\mathrm{O}$ fator de correção (PC/PCVZ) desse experimento apresentou valor médio de 1,09 na faixa de peso e nas condições estudadas. Entretanto, à medida que se elevou o PC, a relação PC/PCVZ também aumentou, em decorrência do enchimento do trato gastrintestinal com o aumento do peso corporal.

O teste de identidade entre os modelos, aplicado às equações de regressão do logaritmo do conteúdo corporal de gordura, proteína e energia, em função do PCVZ, para dieta com ração farelada ou peletizada, indicou não haver diferença significativa entre os concentrados (Tabela 3). Portanto, pode-se recomendar o uso da equação conjunta, tanto para dietas contendo ração farelada ou peletizada.

Franklin et al. (2003), estudando o efeito da forma física do concentrado sobre o desempenho de bezerras no período de aleitamento, verificaram que o consumo e o desempenho 
de bezerros alimentados com concentrado peletizado foram inferiores aos daqueles alimentados com concentrado texturizado e dos bezerros alimentados com concentrado farelado. Gonsalves Neto (2004), testando o uso de ração farelada ou peletizada em bezerros holandeses machos, concluiu que não houve efeito da textura da ração sobre o desempenho dos animais.

Regressão linear significativa ( $\mathrm{P}<0,01)$ foi observada para as equações logarítmicas relativas ao conteúdo corporal de proteína, gordura e energia. Os coeficientes de determinação encontrados neste trabalho para proteína, gordura e energia foram de 95,55; 93,57 e 95,11\%, respectivamente, e comprovam bom ajustamento das equações aos dados experimentais. Esses resultados são superiores aos encontrados por Zervoudakis et al. (2002), que obtiveram $\mathrm{r}^{2}$ de $74 \%$ para proteína, $81 \%$ para gordura e $88 \%$ para energia em novilhos sob suplementação no período das águas, e semelhantes aos obtidos por Carvalho et al. (2003), que obtiveram $\mathrm{r}^{2}$ de $98,10 \%$ para proteína, 95,94\% para gordura e $97,85 \%$ para energia, em pesquisa com bezerros machos de origem leiteira do nascimento aos 110 dias de idade.

A partir da derivação das equações logarítmicas de regressão (Tabela 3) foi possível estimar as exigências

Tabela 3 - Parâmetros das equações de regressão do logaritmo dos conteúdos de proteína $(\mathrm{kg})$, gordura $(\mathrm{kg})$ e energia (Mcal) no corpo vazio, em função do logaritmo do peso de corpo vazio $(\mathrm{kg})$ de bezerros holandeses, e coeficientes de determinação $\left(\mathrm{r}^{2}\right)$

\begin{tabular}{llcl}
\hline Nutriente & \multicolumn{2}{c}{ Parâmetro } & $\mathrm{r}^{2}(\%)$ \\
\cline { 2 - 3 } & Intercepto (a) & Coeficiente (b) \\
\hline Proteína (kg) & $-1,51148$ & 1,4083 & \\
Gordura (kg) & $-2,46518$ & 1,6612 & 95,55 \\
Energia (Mcal) & $-0,659607$ & 1,4583 & 95,57 \\
\hline
\end{tabular}

líquidas de proteína, energia e conteúdo de gordura no ganho de $1 \mathrm{~kg}$ de PCVZ (GPCVZ) para os animais com diferentes PCVZ (Tabela 4).

A relação entre o GPCVZ e GPC foi de 0,78. Portanto, nas condições deste experimento, as exigências para ganho de $1 \mathrm{~kg}$ de PCVZ foram multiplicadas pelo fator 0,78 para se obterem as exigências líquidas para ganho de $1 \mathrm{~kg}$ de PC. O NRC (2001) utiliza a relação 0,89 entre GPCVZ e GPC para novilhas acima de $100 \mathrm{~kg}$ de peso corporal.

Os requisitos líquidos de proteína ( $\mathrm{g} / \mathrm{kg}$ ) aumentaram de 163,38 para 267,10 à medida que se elevou o PCVZ de 25,74 a 85,81 kg, resultando em acréscimo de $63,48 \%$ no conteúdo corporal de proteína, mesmo comportamento do GPC (de 127,43 para 208,34). Isso se justifica pelo fato de os animais estarem em crescimento, com grande desenvolvimento muscular (dos 28 aos 112 dias de idade).

Para os animais com 34,32 kg de PCVZ ganharem $1 \mathrm{~kg}$ de PC, foram necessários 20,36 g de proteína a mais que para aqueles com 25,74 kg de PCVZ, enquanto a diferença para um bezerro de 85,81 kg de PCVZ ganhar $1 \mathrm{~kg}$ de PC foi de apenas 11,24 g superior à do animal pesando 77,23 kg de PCVZ. Essas constatações indicam comportamento linear positivo na exigência de proteína, porém com acréscimos decrescentes, quando o PCVZ aumentou até $85,81 \mathrm{~kg}$.

Carvalho et al. (2003), trabalhando com bezerros machos de origem leiteira do nascimento aos 110 dias de idade, observaram aumento no requisito proteico dos bezerros de 200,60 para 229,21 kg de GPCVZ, quando os animais elevaram seus pesos de 27,57 até 74,27 kg, respectivamente. Esse comportamento foi semelhante ao encontrado por Signoretti et al. (1999), que, em bezerros da raça Holandesa submetidos a níveis crescentes de volumoso na dieta, na faixa de peso de 65,78 a $260 \mathrm{~kg}$ de PCVZ, observaram aumento no requisito proteico para os níveis de 10 e 55\% de volumoso.

Tabela 4 - Exigências líquidas de proteína (g), energia (Mcal) e conteúdo de gordura (g) por kg de ganho de peso de corpo vazio (GPCVZ) e por kg de ganho de peso corporal (GPC) de bezerros holandeses

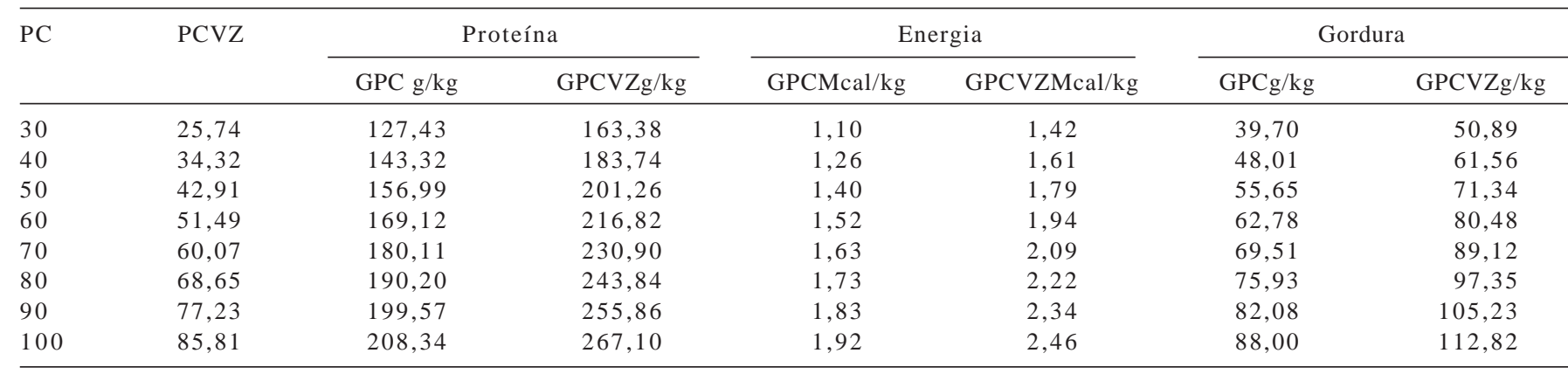

PCVZ $=$ PC * 0,8581

Relação GPCVZ/GPC $=0,78$

$\mathrm{GPC}=\mathrm{GPCVZ} * 0,78$. 
Vasconcelos et al. (1997) atribuíram a animais jovens exigência proteica proporcional elevada, uma vez que esses animais se encontram em pleno desenvolvimento corporal.

Utilizando os dados deste trabalho, foi obtida a seguinte equação para estimar a proteína retida (PR), em g/dia, em função do ganho de peso corporal em jejum (GPCJ), em kg/dia, e energia retida (ER) em Mcal/dia: PR = $-0,297083+4,19797$ GPCJ + 0,0926327ER $\left(R^{2}=0,92\right)$. ONRC (1996) e Véras et al.(2000), para bovinos de corte com idade média de 20 meses, preconizam as equações $\mathrm{PR}=\mathrm{GPCJ}$ (268 - (29,4 (ER/GPCJ))) e PR = 0,416321 + 215,345 GPCJ 14,1352 ER, respectivamente, para estimativa dos requisitos líquidos de proteína para ganho (PR). Silva et al. (2002b) encontraram PR = -39,0169 + 200,638 GPCJ + 0,4166 ER em pesquisa com bovinos Nelore não-castrados alimentados com rações contendo diferentes níveis de concentrado e proteína.

A quantidade de gordura, bem como o requisito líquido de energia para GPC (g/dia), aumentou de acordo com o aumento do peso corporal dos animais. Quando o peso corporal aumentou de 30 para $100 \mathrm{~kg}$, a quantidade de gordura retida mais que dobrou, passando de 39,7 para $88,0 \mathrm{~g} / \mathrm{kg}$ de GPC, semelhantemente ao requisito líquido de energia, que elevou $74,5 \%$, passando de 1,10 para $1,92 \mathrm{Mcal} /$ kg GPC. Carvalho et al. (2003), trabalhando com bezerros na faixa de PC de 30 a 100 kg, observaram acréscimo de 54\% na gordura requerida para GPC e de $20 \%$ para exigências líquidas de energia. Araújo et al. (1998b) encontraram acréscimo de $35,62 \%$ para gordura e de $22 \%$ para energia, quando o peso corporal dos animais aumentou de 60 para $100 \mathrm{~kg}$.

A exigência líquida de energia, estimada pelo AFRC (1993) para bezerros da raça Holandesa com 30 kg de PC, é de1,22 Mcal/kg de GPC. ONRC (1989), no entanto, estima valor $8 \%$ superior para suprir a mesma exigência, de 1,32 Mcal/kg de GPC. A exigência líquida de energia para mantença encontrada nesta pesquisa foi baseada nos dados do NRC (2001) para bezerros de origem leiteira de $30 \mathrm{~kg}$ de PC (1,10 Mcal/kg GPC) e foi 9,8 e 16,7\% inferior às preconizadas pelo AFRC (1993) e NRC (1989), respectivamente.

A equação obtida para descrever a relação entre a energia retida (ER), em Mcal, e ganho diário de PCVZ (GPCVZ), em kg, para determinado PCVZ, conforme recomendado pelo NRC (1996), a partir dos dados deste trabalho, foi a seguinte: $\mathrm{ER}=0,1004 \times \mathrm{PCVZ}^{0,75} \times$ $\operatorname{GDPCVZ}^{0,5552}\left(\mathrm{R}^{2}=0,72\right)$. A partir desta equação, a energia retida de um animal com GPCVZ igual a 1 kg e PC de 90 kg é de 2,61 Mcal/dia.
Utilizando a mesma metodologia, Silva et al. (2002b) trabalharam com bovinos Nelore não-castrados e obtiveram a seguinte equação: $\mathrm{ER}=0,042 \times \mathrm{PCVZ}^{0,75} \times \mathrm{GPCZ}^{1,2257}$ $\left(r^{2}=0,94\right)$, enquanto Veloso et al. (2002) encontraram a equação $\mathrm{ER}=0,038 \times \mathrm{PCVZ}^{0,75} \times \mathrm{GPCVZ}^{0,9896}\left(\mathrm{r}^{2}=0,75\right)$.

As exigências de proteína metabolizável foram calculadas conforme metodologia do NRC (2001) utilizando-se os valores referentes às exigências líquidas de proteína para ganho de peso deste estudo (Tabela 5). O comportamento relativo às exigências de proteína metabolizável para mantença (PMm) e para ganho (PMg) foi semelhante, ou seja, as exigências aumentaram de acordo com o peso corporal dos animais, de 30 para $100 \mathrm{~kg}$, um comportamento esperado, pois exigências proteicas para mantença variam conforme o peso corporal. Comportamento semelhante foi verificado para as exigências de proteína metabolizável total (PMt), que elevaram de 227,78 para 428,34 g/dia nesse intervalo de peso corporal. Para um animal de $90 \mathrm{~kg}$ de peso corporal, a exigência de PMt, segundo dados desse experimento, foi de 403,05 g/dia, 32,8\% superior à recomendada pelo NRC (2001) para bezerros com mesmo peso e taxa de ganho, provavelmente por esses animais apresentarem maior quantidade de músculo no PCVZ.

A partir dos requisitos de proteína metabolizável e utilizando-se as recomendações do NRC (2001) para conversão dos requisitos totais de PMt em exigências de proteína bruta (PB), foi utilizada a fórmula $\mathrm{PB}=\mathrm{PMt} / 0,8645$. Os resultados de PB apresentaram comportamento semelhante ao da PMt, elevando-se com o aumento do peso corporal dos animais.

Tabela 5 - Exigências de proteína metabolizável para mantença (PMm), proteína metabolizável para ganho de peso (PMg), proteína metabolizável total (PMt) e proteína bruta (PB) para ganho de $1 \mathrm{~kg}$ de PCVZ ( $g / k g$ GPCVZ) por bezerros holandeses em função do peso corporal (PC)

\begin{tabular}{lcccc}
\hline Peso corporal & $\mathrm{PMm}^{1}$ & $\mathrm{PMg}^{2}$ & $\mathrm{PMt}$ & $\mathrm{PB}^{3}$ \\
& \multicolumn{4}{c}{$\mathrm{g} / \mathrm{dia}$} \\
\hline 30 & 24,36 & 203,42 & 227,78 & 263,48 \\
40 & 30,54 & 231,74 & 262,28 & 303,39 \\
50 & 36,42 & 257,18 & 293,59 & 339,61 \\
60 & 42,05 & 280,74 & 322,79 & 373,39 \\
70 & 47,51 & 303,01 & 350,52 & 405,46 \\
80 & 52,81 & 324,37 & 377,18 & 436,29 \\
90 & 57,98 & 345,07 & 403,05 & 466,22 \\
100 & 63,04 & 365,30 & 428,34 & 495,48 \\
\hline
\end{tabular}

${ }^{1} \mathrm{PMm}=6,25[1 / 0,764(\mathrm{E}+\mathrm{G}+\mathrm{M} * \mathrm{D})-\mathrm{M} * \mathrm{D}]$, em que $\mathrm{E}=\mathrm{N}$ endógeno da urina $\mathrm{G}=$ conteúdo de $\mathrm{N}$ para ganho; $\mathrm{M}=\mathrm{N}$ metabólico fecal, g/dia; $\mathrm{D}=$ consumo de matéria seca, $\mathrm{kg}$ (NRC, 2001).

2 Exigências líquidas/(0,834-(PC*(478/530)*0,00114) (NRC, 2001).

${ }^{3} \mathrm{~PB}=\mathrm{PMt} / 0,8645$ (NRC (2001). 
Tabela 6 - Exigências diárias de energia líquida para mantença (ELm), energia líquida para ganho (ELg) de $1 \mathrm{~kg}$ de peso corporal de bezerros holandeses

\begin{tabular}{|c|c|c|}
\hline \multirow[t]{2}{*}{ Peso corporal } & ELm & ELg \\
\hline & \multicolumn{2}{|c|}{ Mcal/dia } \\
\hline 30 & 1,10 & 1,42 \\
\hline 40 & 1,37 & 1,61 \\
\hline 50 & 1,62 & 1,79 \\
\hline 60 & 1,85 & 1,94 \\
\hline 70 & 2,08 & 2,09 \\
\hline 80 & 2,30 & 2,22 \\
\hline 90 & 2,51 & 2,34 \\
\hline 100 & 2,72 & 2,46 \\
\hline
\end{tabular}

$\mathrm{ELm}=0,086 * \mathrm{PC}^{0,75}(\mathrm{NRC}, 2001)$.

As exigências líquidas diárias de energia elevaram com o aumento do peso corporal dos animais (Tabela 6). A exigência de ELm para animais com $100 \mathrm{~kg}$ de peso corporal encontrada neste trabalho foi de 2,72 Mcal/dia, resultado superior ao relatado por Araújo et al. (1998a), em pesquisa com bezerros mestiços Holandês $\times$ Zebu, de 2,05 Mcal/dia, e inferior ao encontrado por Signoretti et al. (1999) em bezerros holandeses puros por cruza, de 3,09 Mcal/dia.

A exigência de ELg aumentou de 1,42 para 2,46 Mcal/dia por kg de ganho à medida que o peso corporal de 30 para $100 \mathrm{~kg}$, ou seja, 15,8\% superior à encontrada por Araújo et al. (1998a) com bezerros mestiços com $100 \mathrm{~kg}$ de peso corporal.

A maior exigência de ELm de bovinos da raça Holandesa no início da fase de crescimento pode ser, em parte, explicada pelo maior tamanho de órgãos internos (principalmente fígado e trato gastrintestinal) e pelos maiores depósitos de gordura interna, que possuem atividade metabólica intensa nesta fase de crescimento, e pelo grande potencial de produção (Sollis et al., 1988).

Segundo dados do NRC (2001), bezerros com 30 e $100 \mathrm{~kg}$ de peso corporal possuem ELg estimada de 2,61 e 4,0 Mcal/ dia. No entanto, os dados encontrados neste estudo para estas faixas de peso (1,42 e 2,46 Mcal/dia) foram 45,6\% e $38,5 \%$ inferiores, respectivamente e podem ser explicados pelo fato de os animais utilizados neste experimento terem apresentado maior participação de músculo e menor quantidade de gordura no PCVZ.
Tabela 7 - Exigências diárias de energia metabolizável para mantença (EMm), energia metabolizável para ganho (EMg), energia metabolizável total (EMt), energia digestível (ED) e nutrientes digestíveis totais (NDT) para ganho de $1 \mathrm{~kg}$ de peso corporal de bezerros holandeses

\begin{tabular}{lccccc}
\hline PC & $\begin{array}{r}\text { EMm } \\
\text { Mcal/dia }\end{array}$ & $\begin{array}{c}\text { EMg } \\
\text { Mcal/dia }\end{array}$ & $\begin{array}{c}\text { EMt } \\
\text { Mcal/dia }\end{array}$ & $\begin{array}{c}\text { ED } \\
\text { Mcal/dia }\end{array}$ & $\begin{array}{c}\text { NDT } \\
\mathrm{kg} / \text { dia }\end{array}$ \\
\hline 30 & 1,34 & 2,17 & 3,51 & 3,75 & 0,85 \\
40 & 1,66 & 2,48 & 4,13 & 4,43 & 1,00 \\
50 & 1,96 & 2,74 & 4,70 & 5,04 & 1,14 \\
60 & 2,25 & 2,98 & 5,23 & 5,60 & 1,27 \\
70 & 2,52 & 3,20 & 5,72 & 6,13 & 1,39 \\
80 & 2,79 & 3,40 & 6,19 & 6,63 & 1,50 \\
90 & 3,05 & 3,59 & 6,64 & 7,11 & 1,61 \\
100 & 3,30 & 3,77 & 7,07 & 7,56 & 1,72 \\
\hline
\end{tabular}

$\mathrm{EMm}=\mathrm{ELm} / 0,825$ (NRC, 2001). $\mathrm{EMg}=\mathrm{ELg} / 0,652$ (NRC, 2001). $\mathrm{ED}=\mathrm{EM} /$ 0,934 (NRC, 2001).

NDT $=$ ED/4,409 (NRC, 2001)

O resultado obtido para energia metabolizável para mantença (1,96 Mcal/dia) foi 4,25\% (Tabela 7) superior ao descrito por Davis \& Drackley (1998), de 1,88 Mcal/dia para bezerros de $50 \mathrm{~kg}$ de PV. A exigência de energia metabolizável para ganho elevou de 2,17 para 3,77 Mcal/dia à medida que o peso corporal dos animais analisados aumentou de 30 para $100 \mathrm{~kg}$. Segundo estimativa do NRC (2001), animais com 40 kg de PV apresentam exigência líquida diária de EMg de 3,11 Mcal/dia por kg de peso. A exigência líquida de energia metabolizável encontrada neste trabalho (4,70 Mcal/dia) foi 10,48\% inferior à estimada por Toullec (1989): EM (Mcal/dia) $=0,1 * \mathrm{PV}^{0,75}+$ $\left(0,84 * \mathrm{PV}^{0,355} * \mathrm{GPV}^{1,2}\right)$, de 5,25 Mcal/dia, para animais com 50 kg de PV.

As exigências totais de energia metabolizável (mantença + ganho) e de NDT de um animal pesando $80 \mathrm{~kg}$ de peso corporal e com ganho médio diário (GMD) de $0,7 \mathrm{~kg} / \mathrm{dia}$ foi de $5,8 \mathrm{Mcal} / \mathrm{kg}$ e $1,41 \mathrm{~kg} / \mathrm{dia}$, respectivamente (Tabela 8 ). Os requisitos de energia e NDT foram inferiores aos recomendados pelo NRC (2001), de 6,21 Mcal/kg e 1,51 kg/dia, respectivamente, para bezerros jovens com mesmo peso e taxa de ganho.

Animais com $60 \mathrm{~kg}$ e ganhos de peso de $0,3 \mathrm{~kg} / \mathrm{dia}$ apresentaram exigência de proteína bruta de 170,56 g/dia, resultado 33,16\% superior ao recomendado pelo NRC (2001), de 114 g/dia. 
Tabela 8 - Exigências nutricionais de energia e proteína para bezerros holandeses

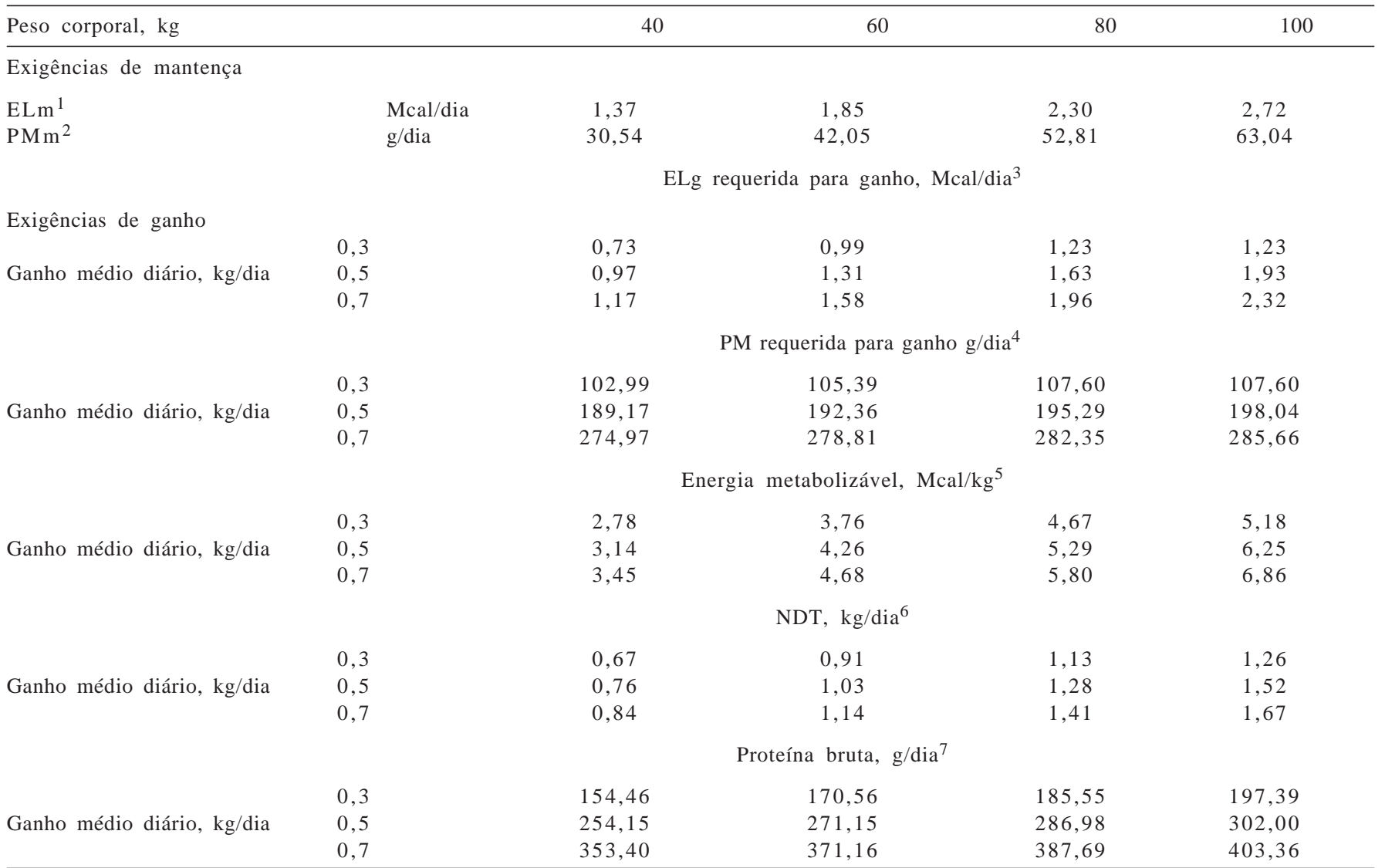

${ }^{1} \mathrm{ELm}=0,086 / \mathrm{PCVZ}^{0,75}$ (NRC, 2001).

$2 \mathrm{PMm}=6,25[1 / 0,764(\mathrm{E}+\mathrm{G}+\mathrm{M} * \mathrm{D})-\mathrm{M} * \mathrm{D}]$, em que $\mathrm{E}=\mathrm{N}$ endógeno da urina; $\mathrm{G}$ = conteúdo de $\mathrm{N}$ para ganho; $\mathrm{M}$ = N metabólico fecal, g/dia; $\mathrm{D}$ = consumo de matéria seca, $\mathrm{kg}$ (NRC, 2001).

${ }^{3} \mathrm{ELg}=0,1004 \times \mathrm{PCVZ}^{0,75} \times \mathrm{GDPCVZ}^{0,5552}$

${ }^{4} \mathrm{PR}=-0,297083+4,19797$ GPCJ $+0,0926327 \mathrm{ER}$.

${ }^{5} \mathrm{EM}=\mathrm{EMm}+\mathrm{EMg}(\mathrm{NRC}, 2001)$

${ }^{6} \mathrm{NDT}=\mathrm{EM} / 0,934 / 4,409$ (NRC, 2001)

${ }^{7} \mathrm{~PB}=\mathrm{PMt} / 0,8645$ (NRC, 2001).

$\mathrm{EMm}=\mathrm{ELm} / \mathrm{EUEMm}$, eficiência de utilização da energia metabolizável de mantença $($ EUEMm) $=0,825$ (NRC, 2001)

EMg = Elg/EUEMg, eficiência de utilização da energia metabolizável para ganho (EUEMg) = 0,652 (NRC, 2001).

\section{Conclusões}

Na fase dos 28 aos 112 dias de idade, ocorrem aumentos de proteína, gordura e energia na composição do corpo vazio de bezerros machos de origem leiteira, além de acréscimos nas exigências líquidas desses nutrientes para ganho de peso corporal. As exigências líquidas de proteína bruta desses animais são superiores e as exigências líquidas de energia, inferiores às recomendadas pelo NRC (2001).

\section{Literatura Citada}

AGRICULTURAL AND FOOD RESEARCH COUNCIL - AFRC. Energy and protein requeriments of ruminants. Wallingford: Commonwealth Agricultural Bureaux International, 1993. 159p.

AGRICULTURAL RESEARCH COUNCIL - ARC. The nutrient requirements of ruminant livestock. Farnham Royal: $C A B$, 1980. 351p.
ARAÚJO, G.G.L.; SILVA, J.F.C.; VALADARES FILHO. S.C. et al. Composição corporal e exigencies líquidas de energia de bezerros. In: REUNIÃO ANUAL DA SOCIEDADE BRASILEIRA DE ZootecniA, 35., 1998, Botucatu. Anais... São Paulo: Sociedade Brasileira de Zootecnia, 1998a. p.332.

ARAÚJO, G.G.L.; SILVA, J.F.C.; VALADARES FILHO, S.C. et al. Composição corporal e exigências líquidas de energia e proteína de bezerros alimentados com dietas contendo diferentes níveis de volumoso. Revista Brasileira de Zootecnia, v.27, n.5, p.1013-1022, 1998b.

ARMSTRONG, D.G.; BLAXTER, K.L. Maintenance requirement: implications for its use in feed evaluation system. In: GILCHRIST, F.M.C., MACKIE, R.I. (Eds.) Herbivore nutrition in the subtropics and tropics. Petroria - South Africa: The Science Press, 1983. p.631-647.

CARVALHO, P.A.; SANCHEZ, L.M.B.; PIRES, C.C. et al. Composição corporal e exigências líquidas de proteína e energia para ganho de peso de bezerros machos de origem leiteira do nascimento aos 110 dias de idade. Revista Brasileira de Zootecnia, v.32, n.6, p.1484-1491, 2003.

DAVIS, C.L.; DRACKLEY, J.K. The development, nutrition, and management of the young. 1.ed. Ames: State University Press, 1998. 329p. 
FRANKLIN, S.T.; AMARAL-PHILIPS, D.M. et al. Health and performance of Holstein calves that suckled or were hand-fed colostrum and were fed one of three physical forms of starter. Journal Dairy Science, v.86, p.2145-2153, 2003.

GONSALVES NETO, J. Desempenho de bezerros da raça holandesa alimentados com concentrado farelado ou peletizado. 2004. 56f. Dissertação (Mestrado em Zootecnia) - Universidade Estadual do Sudoeste da Bahia, Itapetinga, 2004.

KOCK, S.W.; PRESTON, R.L. Estimation of bovine carcass composition by the urea dilution technique. Journal of Animal Science, v.48, n.2, p.319-327, 1979.

LOPES, J.N.P.; CAMPOS, O.F.; LEÃO, M.I. et al. Efeito de dietas à base de leite integral e, ou, subprodutos de soja sobre algumas características relacionadas à digestão, em bezerros. Revista Brasileira de Zootecnia, v.27, n.3, p.603-612, 1998.

NATIONAL RESEARCH COUNCIL - NRC. Nutrient requirements of dairy cattle. 7.ed. Washington, D.C.: National Academy Press, 1989. 157p.

NATIONAL RESEARCH COUNCIL - NRC. Nutrient requirements of dairy cattle. 7.ed. Washington, D.C.: National Academy Press, 2001. 381p.

REGAZZI, J.A. Teste para verificar a identidade de modelos de regressão. Pesquisa Agropecuária Brasileira, v.31, n.1, p.1-17, 1993, 1996.

RIBEIRO JR., J.I. Análises estatísticas no SAEG (Sistema de análises estatísticas). Viçosa, MG: UFV, 2001. 301p.

SIGNORETTI, R.D.; SILVA, J.F.C.; VALADARES FILHO, S.C. et al. Composição corporal e exigências líquidas de energia e proteína de bezerros da raça Holandesa alimentados com dietas contendo diferentes níveis de volumoso. Revista Brasileira de Zootecnia, v.28, n.1, p.195-204, 1999.

SILVA, D.J.; QUEIROZ, A.C. Análise de alimentos: métodos químicos e biológicos. 3.ed. Viçosa, MG: Universidade Federal de Viçosa, 2002. 235p.

SILVA, F.F.; VALADARES FILHO, S.C.; ÍTAVO, L.C.V. et al. Composição corporal e requisitos energéticos e protéicos de bovinos nelore, não-castrados, alimentados com rações contendo diferentes níveis de concentrado e proteína. Revista Brasileira de Zootecnia, v.31, n.1, p.503-513, 2002a (supl.). SILVA, F.F.; VALADARES FILHO, S.C.; ÍTAVO, L.C.V. et al. Eficiência de utilização de energia metabolizável para mantença e ganho de peso de bovinos nelore não-castrados. Revista Brasileira de Zootecnia, v.31, n.1, p.514-521, 2002b (supl.).

SOLLIS, J.C.; BYERS, F.M.; SHELLING, G.T. et al. Maintenance requirements and energetic efficiency of cows of different breed types. Journal of Animal Science, v.66, p.764-773, 1988.

TOULlEC, R. Veal calves. In: JARRIGE, R. (Ed.) Ruminant nutrition. Recommended allowances and feed tables. London: INRA, 1989. 389p.

VAN SOEST, P.J. Nutritional ecology of the ruminant. 2.ed. Ithaca: Cornell University Press, 1994. 476p.

VASCONCELOS, V.R.; RESENDE, K.T.; PIMENTEL, J.C. et al. Cinética de degradação ruminal da proteína de forrageiras do Semi-árido brasileiro em caprinos. In: REUNIÃO ANUAL DA SOCIEDADE BRASILEIRA DE ZOOTECNIA, 34., 1997, Juiz de Fora. Anais... Juiz de Fora: Sociedade Brasileira de Zootecnia, 1997. p.478-480.

VELOSO, C.M.; VALADARES FILHO, S.C.; GESUALDI JR., A. et al. Composição corporal e exigências energéticas e protéicas de bovinos F1 Limousin x Nelore, não-castrados, alimentados com rações contendo diferentes níveis de concentrado. Revista Brasileira de Zootecnia, v.31, n.3, p.1273-1285, 2002.

VÉRAS, A.S.C.; VALADARES FILHO, S.C.; COELHO DA SILVA, J.F. et al. Composição corporal e requisitos energéticos e protéicos de bovinos Nelore, não-castrados, alimentados com rações contendo diferentes níveis de concentrado. Revista Brasileira de Zootecnia, v.29, n.6, p.2379-2389, 2000.

ZERVOUDAKIS, J.T.; PAULINO, M.F.; DETMANN, E. et al. Conteúdo corporal e exigências líquidas de proteína e energia de novilhos suplementados no período das águas. Revista Brasileira de Zootecnia, v.31, n.1, p.530-537, 2002. 